\title{
Bacillus licheniformis Bearing a High Cellulose-Degrading Activity, which was Isolated as a Heat-Resistant and Micro-Aerophilic Microorganism from Bovine Rumen
}

\author{
Naoko Fujimoto ${ }^{1}$, Tomoyuki Kosaka ${ }^{2}$, Toshihiko Nakao ${ }^{3}$ and Mamoru Yamada ${ }^{* 1,2}$ \\ ${ }^{1}$ Applied Molecular Bioscience, Graduate School of Medicine, Yamaguchi University, Ube 755-8505, Japan \\ ${ }^{2}$ Department of Biological Chemistry, Faculty of Agriculture, Yamaguchi University, Yamaguchi 753-8515, Japan \\ ${ }^{3}$ Laboratory of Theriogenology, Department of Veterinary Medicine, Faculty of Agriculture, Yamaguchi University, Ya- \\ maguchi 753-8515, Japan
}

\begin{abstract}
Screening of bovine rumen contents for heat-resistant and micro-aerophilic cellulose-degrading microorganisms was performed on carboxymethyl cellulose (CMC) plates at $37^{\circ} \mathrm{C}-45^{\circ} \mathrm{C}$, and many isolates were found to produce reducing sugars under a static condition. Of those isolates, R8 and R15, which efficiently produced reducing sugars from $\mathrm{CMC}$ at a high temperature, were further examined. Taxonomic analysis classified both strains into Bacillus licheniformis. Comparison with $B$. licheniformis NBRC12200 and Trichoderma reesei NBRC31329 as a type strain under various conditions revealed that R8 and R15 had filter paper- and CMC-degrading abilities, which are absent in the B. licheniformis type strain, and that both isolates produced reducing sugars from CMC more efficiently than did $T$. reesei type strain at a high temperature under a static condition. These results suggest that R8 and R15 have a strong cellulose-degrading ability at a relatively high temperature under a micro-aerophilic condition.
\end{abstract}

Keywords: heat-resistant and micro-aerophilic microorganism, cellulose degradation, bovine rumen, Bacillus licheniformis.

\section{INTRODUCTION}

Global warming has become one of the most serious environmental issues in the world. Consumption of fossil fuel for transportation accounts for 23\% of world energyrelated greenhouse gas emissions [1]. Ethanol fuel made from biomass is thus recognized as a crucial alternative to gasoline, with an advantage in its carbon-neutral nature as a fuel.

Bioethanol, however, is mainly produced from food sources such as corn or sugar cane but not from non-food biomass, so that the cost of food items increases. Of nonfood biomass, cellulose is the most abundant biopolymer, composed of repeating glucose units. Despite its abundance, few organisms have been found to be able to efficiently degrade the polymer due to its recalcitrant nature of insolubility and formation of a crystalline structure. Degradation of the polymer is thus performed with concentrated acid at a high temperature or with costly cellulases. Advanced technology for efficient utilization of cellulose is thus required. High-temperature fermentation with heatresistant microorganisms is expected to become one of such the technologies. The fermentation technology that efficiently produces ethanol at elevated temperatures is thought to have a potential for reducing cooling costs [2]. The technology also has advantages of efficient simultaneous saccharification and fermentation, a continuous shift

*Address correspondence to this author at the Department of Biological Chemistry, Faculty of Agriculture, Yamaguchi University, 1677-1 Yoshida, Yamaguchi, Japan; Tel: +81-83-933-5869; Fax: +81-83-933-5820; E-mail: m-yamada@yamaguchi-u.ac.jp from fermentation to distillation, reducing risk of contamination, and suitability for application in tropical countries [2-4].

Cellulolytic microorganisms are responsible for much of the cellulose degradation in soils, though some insects and mollusks produce their own cellulases to utilize cellulose $[5$, 6]. Recently, metagenomic analyses of cellulose-degrading microorganisms have been performed $[7,8]$, which allow us to understand cellulose metabolism in soils. On the other hand, regarding application for cellulose degradation, many investigators have focused on cellulose-degrading enzymes. These enzymes were improved by site-specific mutagenesis or overexpressed by genetic engineering $[9,10]$. However, since the application of genetically engineered microorganisms is restricted, cellulose-degrading microorganisms naturally isolated are still useful. Many attempts have been made to isolate cellulolytic microorganisms from various places, and relatively strong cellulase producers including Trichoderma, Aspergillus, Pellicularia, Penicillium, Acremonium and Humicola have been isolated [11-15]. However, they were mainly isolated from soils and found to be heat-sensitive microorganisms. Many cellulolytic anaerobic microorganisms such as Ruminococcus albus were isolated from bovine rumen $[16,17]$. There are moderate thermophilic microorganisms with cellulose degradation activity. They are mainly classified into anaerobic microbes including Clostrisium sp. and aerobic microbes including Bacillus sp. [18, 19]. The former microorganisms require removal of oxygen from culture medium and the latter microorganisms require vigorous agitation for oxygen supply. Micro-aerophilic microorganisms that have hardly been isolated can grow at a low oxygen concentration as under a static condition without agitation. Application of such microorgan- 
isms is thus expected to reduce energy input for agitation. Taken together, heat-resistant and micro-aerophilic microorganisms are thought to be applicable for hightemperature fermentation.

Ruminants such as cows, sheep and deer are apparently cellulose-degrading organisms and degrade cellulose by symbiotic rumen microorganisms. The rumen may be an anaerobic environment and this area has been reviewed recently $[20,21]$. The organ as a site for cellulose digestion has unique features of relatively large size and positioning in the alimentary tract. The high constant temperature of around $39{ }^{\circ} \mathrm{C}$, constant $\mathrm{pH}(6.5)$ and anoxic nature of the rumen are also important factors in overall rumen function [22]. The rumen operates in a more-or-less continuous fashion and is thus analogous to a microbial chemostat [20, 21].

These points described above allowed us to screen bovine rumen contents for heat-resistant and micro-aerophilic cellulose-degrading microorganisms. The micro-aerophilisity was examined under a static condition. After several screening steps, we found Bacillus licheniformis strains with an efficient cellulose-degrading activity compared to type strain of Trichoderma reesei at a relatively high temperature under a static condition.

\section{MATERIALS AND METHODS}

\section{Screening for Heat-Resistant and Micro-Aerophilic Cellulose-Degrading Microorganisms}

To isolate heat-resistant and micro-aerophilic cellulosedegrading microorganisms from the bovine rumen, a portion $(10 \mu \mathrm{l})$ of rumen contents was spread onto YNBP $(0.67 \%$ yeast nitrogen base w/o amino acids and ammonium sulfate, $0.02 \%$ peptone) medium plates containing $0.2 \%$ carboxymethyl cellulose (CMC) and $1.7 \%$ agar, and the plates were incubated at various temperatures overnight. Colonies formed at $43{ }^{\circ} \mathrm{C}$ and $45^{\circ} \mathrm{C}$ were repeatedly grown on fresh CMC plates. Colonies on plates were stained with Gram's iodine in a solution of $0.67 \%$ potassium iodine and $0.33 \%$ iodine [23] to observe the ability for degradation of CMC. To measure reducing sugar amount, cells were grown in YNBP liquid medium containing 2\% CMC. After cultivation, the supernatant of the culture medium was obtained by low-speed centrifugation. The reducing sugar amount in the supernatant was determined by the 3,5-dinitrosalicylic acid (DNS) method [13].

\section{Identification of Isolated Microorganisms}

Genomic DNA from isolated strain was prepared according to the conventional procedure [24]. 16S rDNA was amplified by PCR with a primer set of 5'agagttgatcctggctcag-3' and 5'-aaaggaggtgatccagcc-3' and the prepared genomic DNA as a template. The amplified DNA was subjected to DNA sequence reaction with a primer of 5'-gtccattgcggaagattc-3', 5'-actctctggtctgtaac-3', 5'-tagtaatcgcggatcagc-3', or 5'-aatgcgtttgctgcagca-3' and then applied to the DNA sequencer. The determined sequences were aligned with those of other bacteria by CLC sequence viewer version 6 (CLC bio) to construct phylogenetic trees. The stability of branches in the trees was checked by bootstrapping [25]. The sequence of the gene from $16 \mathrm{~S}$ rRNA of strain R8 and R15 were deposited in the
GenBank/DDBJ database under the following accession numbers: B. licheniformis R8 AB592329 and B. licheniformis R15 AB592330.

\section{Preparation of Crude Cellulase and Zymogram Analysis}

Cells were grown in YNBP medium containing 2\% CMC at $43{ }^{\circ} \mathrm{C}$ for $72 \mathrm{~h}$. The medium fraction was then recovered by low-speed centrifugation, and ammonium sulfate (516 g/l) was added to the fraction to attain $75 \%$ saturation. The resultant precipitated proteins were collected by centrifugation at 20 , $000 \mathrm{xg}$ for $20 \mathrm{~min}$ and dissolved in $140 \mathrm{mM} \mathrm{NaCl}$ and $12 \mathrm{mM}$ sodium phosphate (PBS), $\mathrm{pH} 7.4$, with $1 \mathrm{mM}$ phenylmethylsulfonyl fluoride. The solution was used as the crude cellulase fraction. Protein concentration was determined by the Dully and Grieve method with bovine serum albumin as a standard [26]. Zymogram analysis was performed as described previously with slight modifications [16]. Crude cellulase samples $(10 \mu \mathrm{g})$ were treated by heating at $95^{\circ} \mathrm{C}$ for $2 \mathrm{~min}$ in $1 \%$ SDS and $5 \% \beta$-mercaptoethanol and then applied to a $10 \%$ SDSPAGE gel containing $0.1 \% \mathrm{CMC}$ polymerized within the gel matrix. Following electrophoresis, the gel was washed once

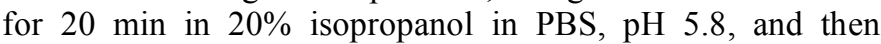
washed three times with PBS. The gel was incubated at $55^{\circ} \mathrm{C}$ in PBS for $1 \mathrm{~h}$, stained with $0.1 \%$ congo red $(1 \mathrm{mg} / \mathrm{ml})$ for 30 min, and destained with $1 \mathrm{M} \mathrm{NaCl}$. Endoglucanase activity was detected as a clear band against a red background.

\section{Determination of Cellulose-Degrading Activity}

Cellulose-degrading activity of the crude cellulase fraction prepared as described above was determined by measuring reducing sugars from degradation of a filter paper or CMC. The reducing sugar amount was measured using a modification of the DNS assay [27]. To measure filter paper degrading activity (FPase), crude cellulase fraction $(0.5 \mathrm{ml})$ was added to $1.0 \mathrm{ml}$ citrate buffer of $0.05 \mathrm{M}$ sodium citrate, $\mathrm{pH} 4.8$, in a test tube and a filter paper strip $\{1 \times 6 \mathrm{~cm}(50 \mathrm{mg})$ of Whatman No.1 filter paper\} was then added into the tube. After brief mixing to form a coiled paper, the reaction was performed by standing the tube at $50{ }^{\circ} \mathrm{C}$ for $1 \mathrm{~h}$. The reaction was stopped by the addition of $3 \mathrm{ml}$ of DNS reagent and heating in boiling water for $5 \mathrm{~min}$. To measure CMCase activity, crude cellulase fractions $(50 \mu \mathrm{l})$ was mixed with $0.95 \mathrm{ml}$ of $0.1 \mathrm{M}$ citrate buffer, $\mathrm{pH} 4.8$, and $1 \mathrm{ml}$ of $2 \% \mathrm{CMC}$. The reaction was performed by incubation at $50{ }^{\circ} \mathrm{C}$ for $10 \mathrm{~min}$ and stopped by the addition of $3 \mathrm{ml}$ of DNS reagent followed by heating in boiling water for $5 \mathrm{~min}$. One unit of enzyme activity was defined as the amount of enzyme that liberated $1 \mathrm{~g}$ of glucose in $10 \mathrm{~min}$ under the conditions tested.

\section{RESULTS}

\section{Screening of Bovine Rumen Contents for Heat-Resistant Cellulolytic Microorganisms}

Bovine rumen contents were screened to isolate heatresistant and micro-aerophilic cellulose-degrading microorganisms. Rumen contents from three bovines were spread onto YNBP plates containing $0.2 \% \mathrm{CMC}$ and incubated at $37{ }^{\circ} \mathrm{C}$ to $45{ }^{\circ} \mathrm{C}$ overnight. Colonies were found at almost all temperatures in each sample (Fig. 1), but the patterns of colony appearance in the range of temperatures tested were slightly different. In the case of bovine 1,96\% of the colonies were obtained at temperatures over $40{ }^{\circ} \mathrm{C}$. In bovine 3 , colonies were found in the temperature range of $39{ }^{\circ} \mathrm{C}$ to $43{ }^{\circ} \mathrm{C}$. In bovine 2 , 


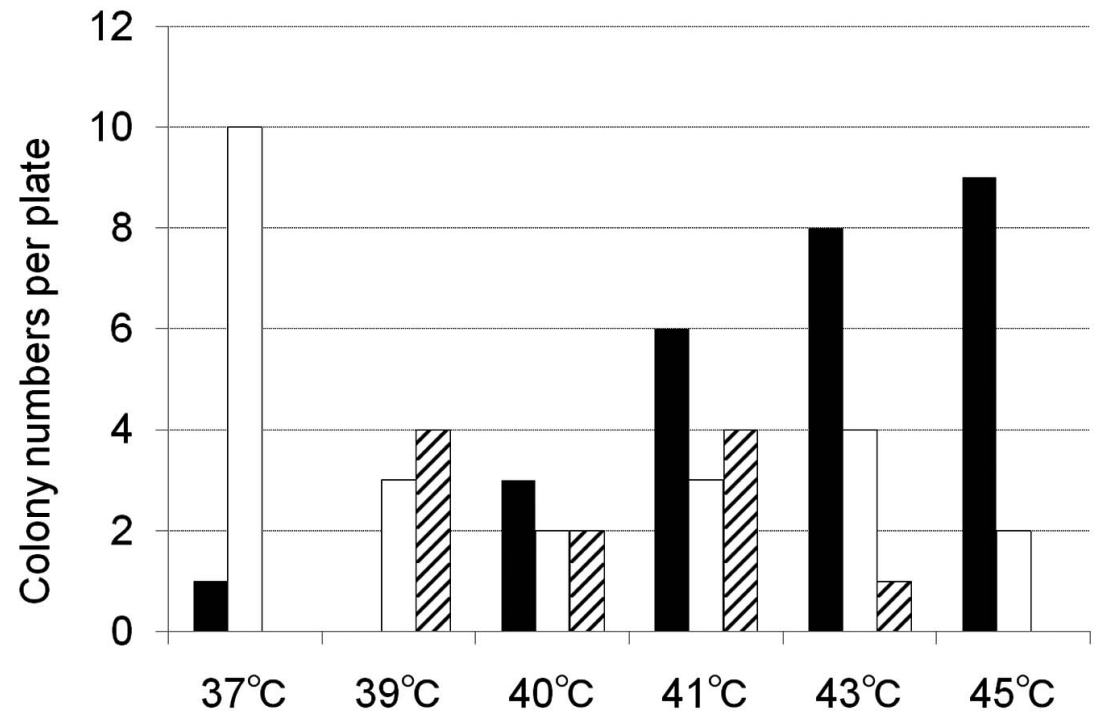

Fig. (1) Appearance frequency of colony on CMC plates at relatively high temperatures. A portion (10 $\mu$ l) of rumen contents was spread onto YNBP medium plates containing $0.2 \% \mathrm{CMC}$ and incubated at 37 to $45{ }^{\circ} \mathrm{C}$ overnight. Colony number was then counted. Black, white, and oblique columns represent bovine 1 , bovine 2 , and bovine 3 , respectively.

colonies were found at all temperatures. From these patterns, we further examined 16 isolates (R1-R16) from the bovine 1 plates, of which $\mathrm{R} 1$ to $\mathrm{R} 8$ and $\mathrm{R} 9$ to $\mathrm{R} 16$ were from plates at $43{ }^{\circ} \mathrm{C}$ and at $45^{\circ} \mathrm{C}$, respectively.

To compare the heat-resistance of the 16 isolates and evaluate the cellulose degradation capability, they were grown on $0.2 \% \mathrm{CMC}$ plates at $43{ }^{\circ} \mathrm{C}$ or $45^{\circ} \mathrm{C}$ overnight and stained with Gram's iodine (Fig. 2a). They formed colonies of similar sizes at both temperatures and exhibited a strong positive color in the Gram's iodine test. Therefore, all 16 isolates were subjected to the following experiments.

\section{Comparison of CMC Degradation Capabilities of Isolates}

To further evaluate cellulose degradation capability, the production of reducing sugars from CMC was compared. The 16 isolates were grown in $2 \% \mathrm{CMC}$ medium at $43{ }^{\circ} \mathrm{C}$ under static and shaking conditions. Reducing sugars more than the background were detected in all medium fractions tested (Fig. 2b). The results revealed that all isolates were able to degrade CMC relatively well under the static condition but very weakly under the shaking condition. R8 and R15 showed relatively high levels of reducing sugar production among the isolates tested. Additionally, both showed faster reduction in viscosity of the culture medium, indicating CMC degradation [28]. We thus selected R8 and R15 as strains with efficient CMC degradation capability.

\section{Characterization of the Isolated Strains R8 and R15}

Taxonomic analysis was carried out and the result clearly showed that R8 and R15 belong to Bacillus licheniformis (Fig. 3). We thus compared R8 and R15 with a type strain of B. licheniformis, NBRC12200, for growth capability and for reducing sugar and ethanol concentrations in media when grown in $2 \% \mathrm{CMC}$ medium at $43{ }^{\circ} \mathrm{C}$ under a static condition (Fig. 4). R8 and R15 grew well compared to NBRC12200. The reducing sugar concentrations of R8 and R15 increased as their growth proceeded, but no reducing sugar was detected in NBRC12200. Moreover, a very small amount of ethanol was detected in the culture medium from $\mathrm{R} 8$ and $\mathrm{R} 15$. Therefore, it is likely that $\mathrm{R} 8$ and $\mathrm{R} 15$ are $B$. licheniformis with CMC degradation capability.

\section{Characterization of Cellulases in Crude Cellulase Fraction}

Since many cellulolytic microorganisms are known to produce various extracellular enzymes to degrade cellulose, the possibility of R8 and R15 being able to produce cellulases was examined. Cells were grown in $2 \% \mathrm{CMC}$ medium at $43{ }^{\circ} \mathrm{C}$ for $48 \mathrm{~h}$ under a static condition, and cellulose-degrading activity was measured after preparation of crude cellulase fractions from the medium fraction as described in Materials and Materials and Methods (Fig. 5a). Crude cellulase fractions from the R8 and R15 culture media showed CMC-degrading activities of $0.07 \mathrm{U} / \mathrm{mg}$ and $0.30 \mathrm{U} / \mathrm{mg}$, respectively, and filter paperdegrading activities of $0.02 \mathrm{U} / \mathrm{mg}$ and $0.10 \mathrm{U} / \mathrm{mg}$, respectively. No such activities were detected in crude cellulase fractions from the NBRC12200 culture medium. In addition, zymogram analysis revealed that a prominent active $37 \mathrm{kDa}$ polypeptide was present in crude cellulase fractions from the R8 and R15 culture media but not in that from the NBRC12200 culture medium (Fig. 5b). These findings suggest that R8 and R15 produce extracellular endoglucanases.

Comparison of the Cellulolytic Abilities of R8 and R15 with that of a Type Strain of Trichoderma reesei at a Relatively High Temperature

$T$. reesei is well known as an efficient cellulase producer $[29,30]$. We thus compared R8 and R15 with a type strain of $T$. reesei NBRC31329, for reducing sugar production from CMC. Cells were grown in $2 \%$ CMC medium at different temperatures under a static condition, and reducing sugar concentration in the medium was then determined (Fig. 6a). Highest reducing sugar concentrations were detected at $40{ }^{\circ} \mathrm{C}$ and 39 ${ }^{\circ} \mathrm{C}$ in $\mathrm{R} 8$ and $\mathrm{R} 15$, respectively, and the level was maintained at least up to $43{ }^{\circ} \mathrm{C}$. A relatively high reducing sugar concentration was seen at $30{ }^{\circ} \mathrm{C}$ to $37{ }^{\circ} \mathrm{C}$ in $T$. reesei, and the concentration became very low at temperatures over $40{ }^{\circ} \mathrm{C}$. We also compared the reducing sugar production abilities of these 


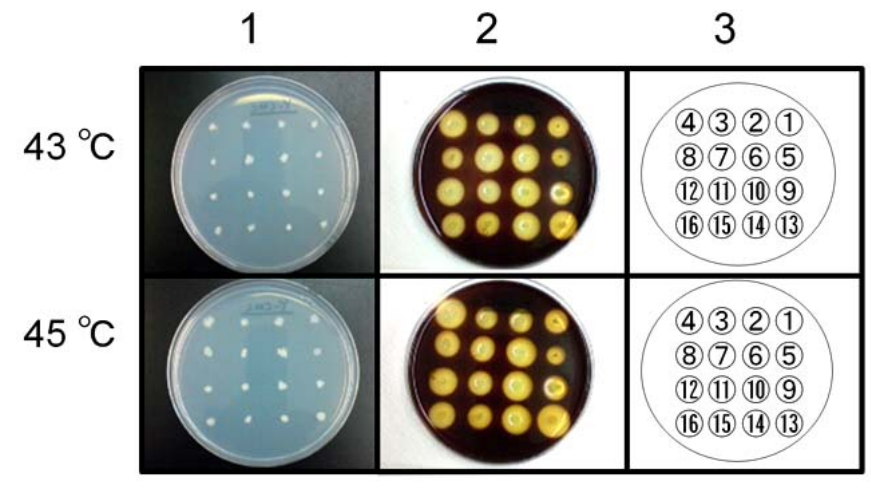

b

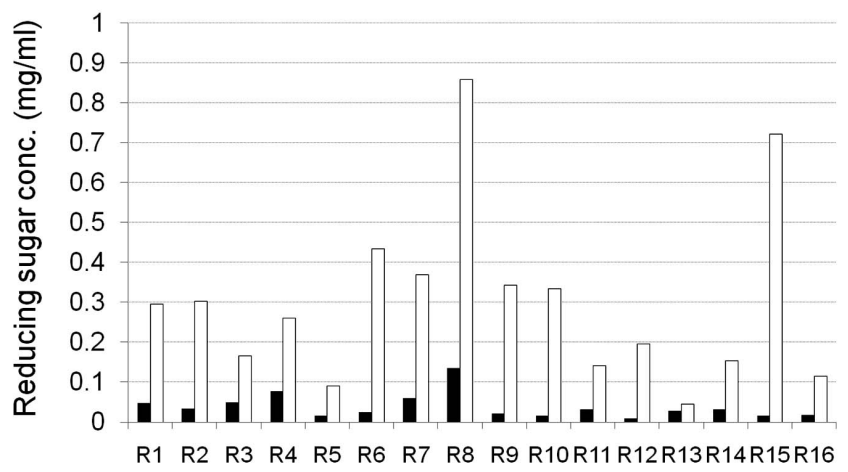

Rumen microorganisms

Fig. (2) Screening of relatively efficient cellulolytic microorganisms. a) R1-R16 isolates were grown on $0.2 \% \mathrm{CMC}$ plates at $43{ }^{\circ} \mathrm{C}$ or $45{ }^{\circ} \mathrm{C}$ overnight and subjected to the Gram's iodine staining. a-1 and a-2 show the growth and staining, respectively.a-3 represents the positions of isolates on plates. b) To compare reducing sugar production, R1-R16 isolates were incubated in $2 \%$ CMC-containing liquid medium at $43{ }^{\circ} \mathrm{C}$ for $48 \mathrm{~h}$ under shaking (black columns) or static (white columns) conditions. Reducing sugar contents were then determined.

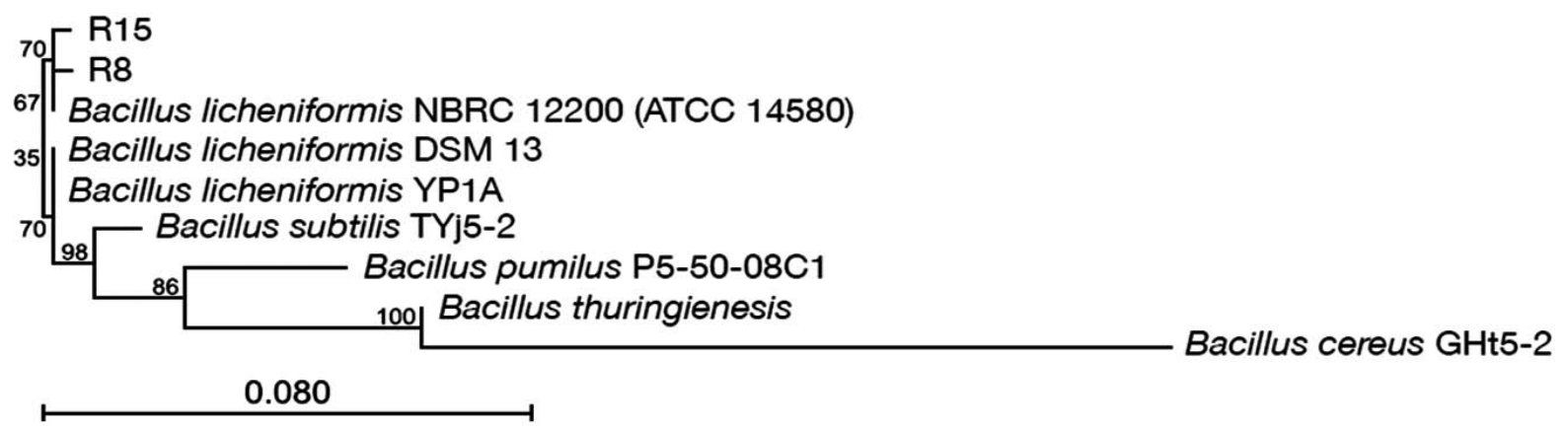

Fig. (3) Phylogenetic tree based on 16S rDNA sequences of R8, R15 and selected Bacillus species. Determined 16S rDNA sequences of R8 and R15 were aligned with those of selected Bacillus species by CLC sequences viewer version 6 and a phylogenetic tree was constructed. The stability of branches in the tree was checked by bootstrapping.
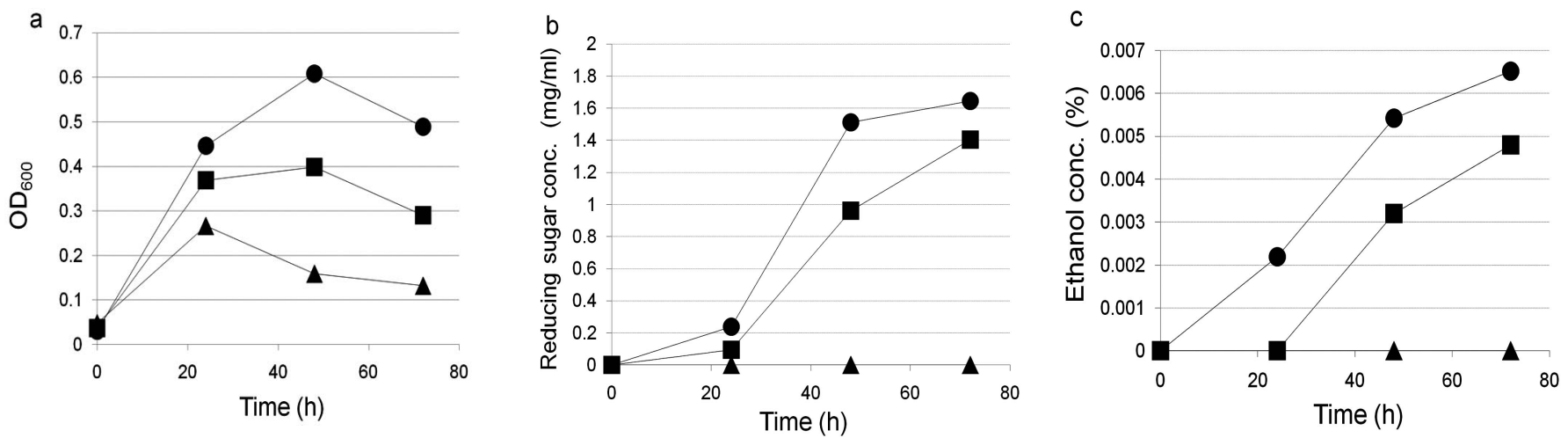

Fig. (4) Comparison of R8 and R15 with a type strain of B. licheniformis NBRC12200 on growth, reducing sugar production and ethanol production. Cells were grown in $2 \% \mathrm{CMC}$ medium at $43{ }^{\circ} \mathrm{C}$ under a static condition, $\mathrm{OD}_{600}$ (a) and reducing sugar (b) and ethanol (c) concentrations in medium were determined at the times indicated. Circles, squares, triangles represent R8, R15 and NBRC12200, respectively.

strains under a shaking condition (Fig. 6b). Similar levels of reducing sugar concentrations were detected in $\mathrm{R} 8$ and R15 under static and shaking conditions at $30^{\circ} \mathrm{C}$ and $37^{\circ} \mathrm{C}$ except for in $\mathrm{R} 8$ under a shaking condition at $37^{\circ} \mathrm{C}$. On the other hand, in $T$. reesei, the reducing sugar concentration was high at a relatively low temperature under a shaking condition. Taken together, the results suggest that R8 and R15 have potential for degradation of cellulose at a relatively high temperature. 


$$
\text { a }
$$

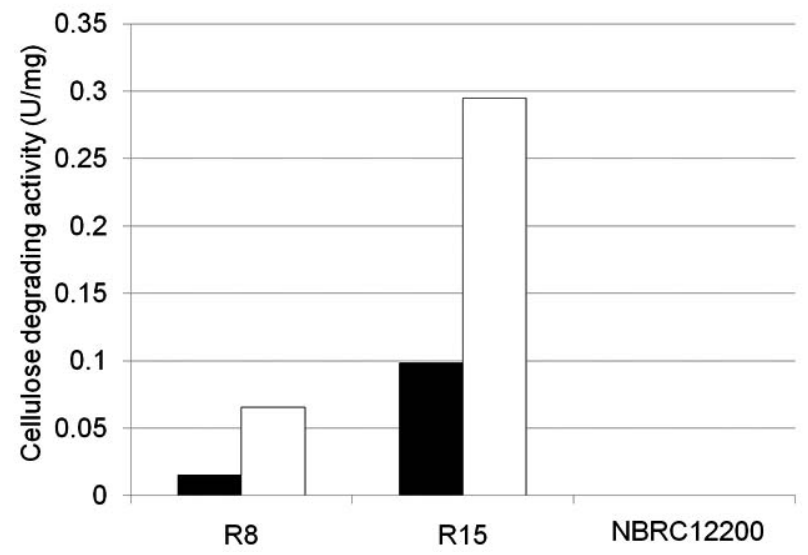

b

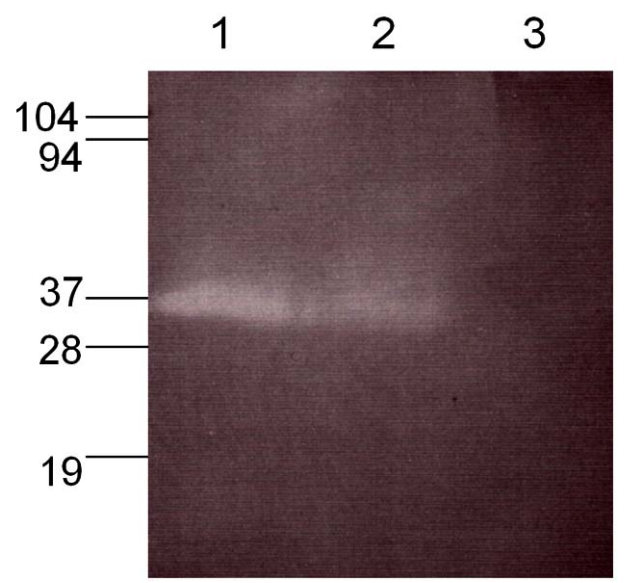

Fig. (5) Comparison of R8 and R15 with a type strain of B. licheniformis NBRC12200 on cellulose-degrading activity and endoglucanases production. a) Cells were grown in $2 \% \mathrm{CMC}$ medium at $43{ }^{\circ} \mathrm{C}$ under static condition, crude cellulase fractions were prepared from culture medium fractions, and activities of FPase (black columns) and CMCase (white columns) were measured as described in Materials and Methods. b) Zymogram analysis was carried out with $10 \mu \mathrm{g}$ each of crude cellulase fractions as described in Materials and Methods. Lanes 1 to 3 are R8, R15 and NBRC12200, respectively. In the original picture, many weak bands above a $37 \mathrm{kDa}$ major band were detected in lane 2 but not in lane 1 .

a

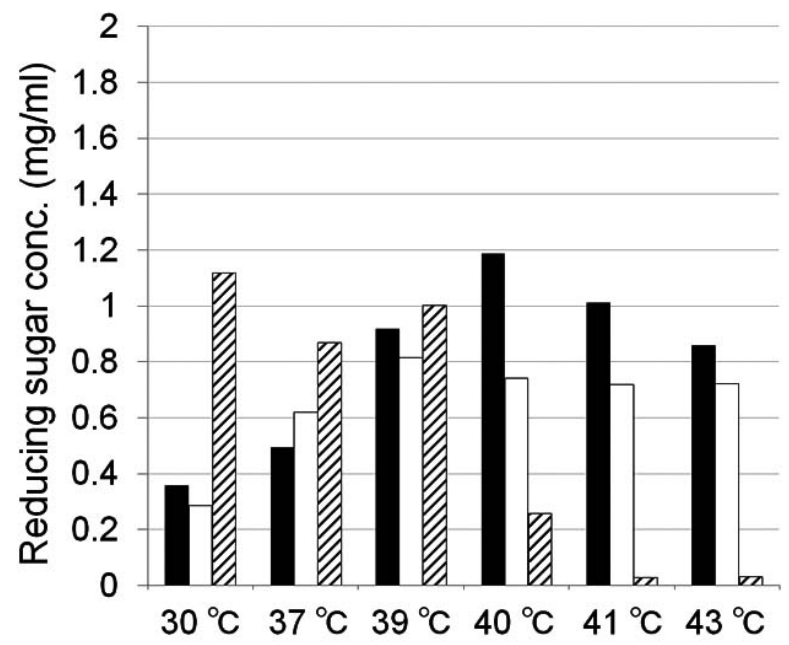

b

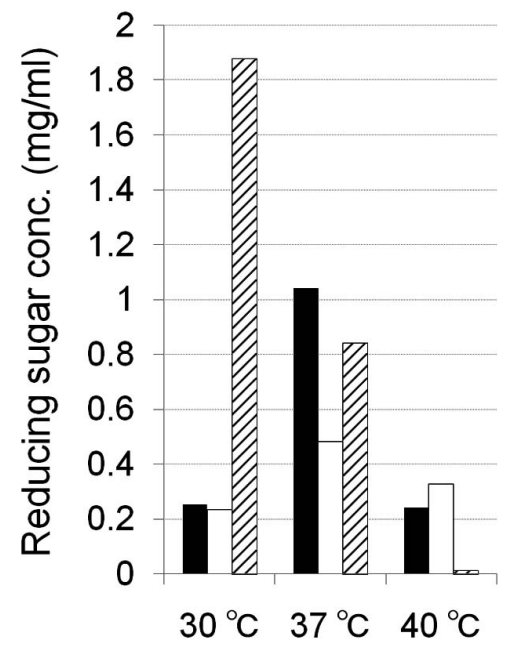

Fig. (6) Comparison of R8 and R15 with a type strain of T. reesei NBRC31329 on reducing sugar production at various temperatures. Cells were grown in $2 \% \mathrm{CMC}$ medium at various temperatures for $72 \mathrm{~h}$ under static (a) and shaking (b) conditions and the reducing sugar in medium was then determined. Black, white, oblique columns represent R8, R15 and T. reesei NBRC31329, respectively.

\section{DISCUSSION}

We attempted to isolate heat-resistant and microaerophilic cellulose-degrading microorganisms that are expected to be beneficial for bio-production of useful materials at a relatively high temperature. Such trials were performed with various soils in our prefecture without success. The presented data suggest that there are microorganisms in the bovine rumen that can grow at $40-45{ }^{\circ} \mathrm{C}$ by utilizing $\mathrm{CMC}$ as a carbon source. The bovine rumen might thus be a suitable environment for heat-resistant and microaerophilic cellulose-degrading microorganisms. Isolates from the bovine rumen prefer a static condition to a shaking condition for growth and reducing sugar production at a relatively high temperature. These findings suggest that the rumen environment is micro-aerophilic and has a rela- tively high temperature. The preference of the isolates is also beneficial since aeration in the bio-production process is also costly.

Taxonomic analysis suggests that two isolated strains, R8 and R15, are B. licheniformis. Unlike most other bacilli, which are predominantly aerobic, B. licheniformis is a facultative anaerobe, which may allow it to grow in additional ecological niches [31].

However, growth of R8 and R15 was much better than that of B. licheniformis type strain NBRC12200 under a static condition (data not shown). Therefore, both strains are less aerophilic than the type strain. Moreover, the two strains have a CMC-degrading activity higher than that of $T$. reesei NBRC31329, a well-known efficient cellulolytic organism, at 
a relatively high temperature, and also have a cellulosedegrading capability. R8 and R15 were shown to produce active $37 \mathrm{kDa}$ endoglucanase which was not observed in the $B$. licheniformis NBRC12200. Since the type strain possesses a gene for endoglucanase on its genome [31], production of the enzyme may require conditions different from those tested in this study. The family 5 endoglucanase with a molecular mass of $37 \mathrm{kDa}$ from a thermophilic strain of B. licheniformis was purified and characterized [19]. The strain, however, could not grow on CMC medium without supplements of glucose and xylose. In contrast, R8 and R15 are able to grow on CMC as a sole carbon source. Therefore, it is likely that R8 and R15 have acquired some abilities to utilize cellulose without supplements of these sugars. Our preliminary experiments showed that R8 and R15 produced reducing sugars from rice straw at a relatively high temperature under a static condition. Therefore, both strains may be useful for application of raw cellulosic materials.

Although both strains isolated possess the capability for cellulose degradation, they are assumed to produce different types of cellulolytic enzymes. Growth and reducing sugar profiles presented in Fig. (4) revealed that R8 produced reducing sugars more than did R15 and showed better growth. Contrary results are shown in Fig. (5), where the cellulose-degrading activity of the crude cellulase fraction from R15 was much higher than that from R8. This discrepancy might be due to the difference in enzyme stability, since cellulose-degrading activities were measured at $50{ }^{\circ} \mathrm{C}$, which was much higher than the temperature for cell cultivation. Alternatively, R8 might produce $\beta$ glucosidase or cellobiohydolase more efficiently to support better growth.

HPLC analysis revealed that there are oligo-sugars in addition to a very small amount of ethanol but almost no glucose in culture media of R8 and R15. The results allow us to speculate that the rate-limiting step of cellulose degradation is either the extracellular process from oligosugars to glucose or the import of oligo-sugars into cells for further catabolism. Our data suggest that R8 and R15 secrete extracellular endoglucanases, which are involved in degradation of CMC to cello-oligosaccharide. The metabolism following the endoglucanases reaction remains to be defined.

\section{CONCLUSION}

New B. licheniformis strains, R8 and R15, that could be employed for degradation of cellulose at a relatively high temperature. Both strains were able to grow in CMC as a sole carbon source and efficiently degraded CMC to reducing sugars at a high temperature. The latter ability was remarkably greater than that of an efficient type strain of $T$. reesei. We thus expect that the combination of $\mathrm{R} 8$ or $\mathrm{R} 15$ and heat-resistant yeast will be applicable for hightemperature ethanol fermentation.

\section{ACKNOWLEDGEMENTS}

We thank K. Matsushita and T. Yakushi for their helpful discussion. This work was supported in part by the New Energy and Industrial Technology Development Organization (NEDO), by the Program for Promotion of Basic Re- search Activities for Innovative Biosciences (PROBRAIN), by The Asian Core Program between Yamaguchi University and Khon Kaen University, which was granted by the Japan Society for the Promotion of Science and the National Research Council of Thailand and by The Asia-Africa Science and Technology Strategic Cooperation Promotion Program by the Special Coordination Funds for Promoting Science \&Technology.

\section{REFERENCES}

[1] Ribeiro KS, Kobayashi S, Beuthe M, et al. Transport and its infrastructure. In Climate Change: Mitigation. Contribution of Working Group III to the Fourth Assessment Report of the Intergovernmental Panel on Climate Change : Metz B, Davidson OR, Bosch PR, Dave R, Meyer LA Eds. Cambridge University Press, Cambridge, United Kingdom and New York, NY, USA 2007.

[2] Banat IM, Nigam P, Singh D, Marchant R, McHale AP. Ethanol production at elevated temperatures and alcohol concentrations: Part I - Yeasts in general. World J Microb Biot 1998; 14(6): 809-21.

[3] Anderson PJ, McNeil K, Watson K. High-efficiency carbohydrate fermentation to ethanol at temperatures above $40{ }^{\circ} \mathrm{C}$ by Kluyveromyces marxianus var. marxianus Isolated from Sugar Mills. Appl Environ Microbiol 1986; 51(6): 1314-20.

[4] Limtong S, Sringiewa C, Yongmanitchaia W. Production of fuel ethanol at high temperature from sugar cane juice by a newly isolated Kluyveromyces marxianus. Bioresour Technol 2007; 98 (17): 336774.

[5] Breznak JA. Intestinal microbiota of termites and other xylophagous insects. Annu Rev Microbiol 1982; 36: 323-43.

[6] Ohkuma M. Termite symbiotic systems: efficient bio-recycling of lignocelluloses. Appl Microbiol Biotech 2003; 61: 1-9.

[7] Flint HJ, Bayer EA, Rincon MT, Lamed R, White BA. Polysaccharide utilization by gut bacteria: potential for new insights from genomic analysis. Nat Rev Microbiol 2008; 6: 121-31.

[8] Pang H, Zhang P, Duan CJ, Mo XC, Tang JL, Feng JX. Identification of cellulase genes from the metagenomes of compost soils and functional characterization of one novel endoglucanase. Curr Microbiol 2009; 58 (4): 404-8.

[9] Nia J, Takehara M, Watanabe H. Identification of activity related amino acid mutations of a GH9 termite cellulase. Bioresour Technol 2010; 101(16): 6438-43.

[10] Rarman Z, Shida Y, Furukawa T, et al. Application of Trichoderma reesei cellulase and xylanase promoters through homologous recombination for enhanced production of extracellular $\beta$-glucosidase I. Biosci Biotechnol Biochem 2009; 73 (5): 1083-9.

[11] Folan MA, Coghlan MP. The saccharifying ability of the cellulase complex of Talaromyces emersonii and comparison with that of other fungal species. Int J Biochem 1979; 10: 505-10.

[12] Hayashida S, Yoshioka H. Production and purification of thermostable cellulases from Humicola insolens YH-8. Agric Biol Chem 1980; 44(8): 1721-8.

[13] Mandels M, Andreonoffi RE. Problems and challenges in the cellulose to cellulase fermentation. Proc Biochem 1978; 13: 6.

[14] Murao S, Kanamoto J, Arai M. Isolation and identification of a cellulolytic enzyme producing microorganism. J Ferment Technol 1979; 57: 151-6.

[15] Taniguchi M, Tanaka M, Matsuno R, Kamikubo T. Effect of culture conditions on cellulase production by Pellicularia filamentosa. J Ferment Technol 1980; 58: 143-8.

[16] Hungate RE. The Rumen and Its Microbes. New York and London: Academic Press 1966; pp. 8-90.

[17] Smith WR, Yu I, Hungate RE. Factors affecting cellulolysis by $R u$ minococcus albus, J Bacteriol 1973; 114(2): 729-37.

[18] Schwarz WH. The cellulosome and cellulose degradation by anaerobic bacteria. Appl Microbiol Biotechnol 2001; 56(5-6): 634-49.

[19] Biscoff KM, Rooney AP, Li X-L, et al. Purification and characterization of a family 5 endoglucanase from a moderately thermophilic strain of Bacillus licheniformis. Biotechnol Lett 2006; 28: $1761-5$.

[20] Lynd LR, Weimer PJ, Van Zyl WH, Pretorius IS. Microbial cellulose utilization: fundamentals and biotechnology. Microbiol Mol Biol Rev 2002; 66: 506-77.

[21] Desvaux M. Unraveling carbon metabolism in anaerobic cellulolytic bacteria. Biotech Prog 2006; 22: 1229-38. 
[22] Madigan MT, Martinko JM, Parker J. Brock biology of microorganisms. $9^{\text {th }}$ ed. New Jersey: Pretice Hall International. Upper Saddle River 2000.

[23] Kasana RC, Salwan R, Dhar H, Dutt S, Gulati A. A rapid and easy method for the detection of microbial cellulases on agar plates using Gram's iodine. Curr Microbiol 2008; 57: 503-7.

[24] Sambrook J, Russell DW. Molecular cloning: a laboratory manual. New York: Cold Spring Harbour Laboratory Press, Cold Spring Harbour 2001.

[25] Felsenstein J. Phylogenies from molecular sequences: inference and reliability. Annu Rev Genet 1988; 22: 521-65.

[26] Dulley JR, Grieve PA. A simple method for eliminating interferences by detergents in the Lowry method of protein determination. Anal Biochem 1975; 64: 136-41.
[27] Acebal C, Castillon MP, Estrada P, et al. Enhanced cellulase production from Trichoderma reesei QM 9414 on physically treated wheat straw. Appl Microbiol Biotechnol 1986; 24: 218-23.

[28] Reese ET, Siu RGH, Levinson HS. The biological degradation of soluble cellulose derivatives and its relationship to the mechanism of cellulose hydrolysis. J Bacteriol 1950; 59(4): 485-97.

[29] Reese ET. History of the cellulase program at the U.S. Army Natick Development Center. Biotechnol Bioeng Symp 1976; 6: 9-20.

[30] Ghosh A, Ghosh BK, Trimino-vazquez H. Cellulase secretion from a hyper-cellulolytic mutant of Trichoderma reesei Rut-C30. Arch Microbiol 1984; 140: 126-33.

[31] Michael WR, Preethi R, Beth AN, et al. Complete genome sequence of the industrial bacterium Bacillus licheniformis and comparisons with closely related Bacillus species. Genome Biol 2004; 5: r77

(C) Fujimoto et al.; Licensee Bentham Open.

This is an open access article licensed under the terms of the Creative Commons Attribution Non-Commercial License (http://creativecommons.org/licenses/by-nc/3.0/) which permits unrestricted, non-commercial use, distribution and reproduction in any medium, provided the work is properly cited. 